Email : jianfis.unp@gmail.com Vol.2 No.1 Maret 2019

\title{
PENGARUH KUALITAS PELAYANAN TERHADAP KEPERCAYAAN PESERTA PBPU BPJS KESEHATAN PADA BPJS KESEHATAN CABANG PADANG DI KOTA PADANG
}

\author{
Yossi Lusiana \\ Jurusan Ilmu Administrasi Negara, Fakultas Ilmu Sosial, Universitas Negeri Padang \\ ochilusianabkt93@gmail.com \\ Aldri Frinaldi \\ Jurusan Ilmu Administrasi Negara, Fakultas Ilmu Sosial, Universitas Negeri Padang \\ alfrinaldi@gmail.com/aldri@fis.unp.ac.id \\ Nora Eka Putri \\ Jurusan Ilmu Administrasi Negara, Fakultas Ilmu Sosial, Universitas Negeri Padang \\ noraekaputri@fis.unp.ac.id
}

\begin{abstract}
The puspose of this research is to examine the influence between the quality of service towards trust of participants of BPJS Health Care in Padang which in class of Workers Not Wage Receivers or Independent Workers. The type of research is assosiative. Population in this research are amounted to 155.669 people. The sampling technique is accidental sampling. Sample in this research are amounted to 398 people. Data collecting using a questionnaire based on a Likert scale that has been tested for validity and reliability. The results showed the public's assessment of the quality of BPJS Health Care participant services and trust in Padang rated high (74.78\% and $72.60 \%)$. There is significant influence between tangible and trust with 0.004 significant value. These hyphoteses were tested by using Model Summary and the Ajusted $R$ Square value of 0.57. There is no significant influence partially between reliability and trust with 0.300 significant value. There is no significant influence between responsiveness and trust on a 0.117 significant value. There is significant influence between assurance and trust with 0.000 significant value. These hyphoteses were tested by using Model Summary and the Ajusted $R$ Square value of 0.112. There is significant influence between emphaty and trust with 0.024 significant value. These hyphoteses were tested by using Model Summary and the Ajusted $R$ Square value of 0.88. There are significant influence simultaneously between tangible, reliability, responsiveness, assurance, emphaty variables and trust on 0.000 significant value and the Ajusted $R$ Square value of 0.168 that means the contribution quality of service to trust is $16.8 \%$.
\end{abstract}

Keywords: Quality of service, Tangible, Responsiveness, Assurance, Emphaty, Trust participants of Independent Workers 


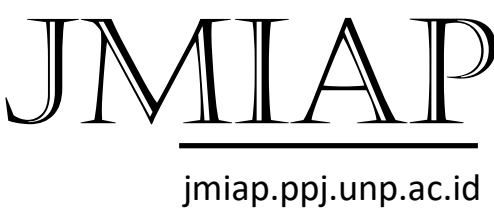

\section{Pendahuluan}

Jaminan Kesehatan Nasional (JKN) merupakan bagian dari sistem jaminan sosial nasional dengan mengunakan mekanisme asuransi kesehatan sosial yang berdasarkan Undang-Undang Nomor 40 Tahun 2004 tentang Sistem Jaminan Sosial Nasional (SJSN) yang mana bertujuan untuk memenuhi kebutuhan dasar kesehatan masyarakat yang layak yang diberikan kepada setiap orang yang telah membayar iuran atau iurannya dibayar pemerintah. Pelaksanaan program-program SJSN telah berjalan dengan cukup baik seperti Jaminan Kesehatan Masyarakat dan Jaminan Sosial Tenaga Kerja (Jamsostek) pekerja formal, Askes bagi PNS atau pensiunan PNS dan keluarganya, Asuransi Pegawai Negeri (Taspen), Asuransi ABRI atau ASABRI.

Namun pelaksanaan sistem jaminan social bidang kesehatan mengalami beberapa masalah dan masih terdapat 36,8 persen masyarakat Indonesia yang belum memiliki jaminan kesehatan apapun, khususnya pekerja pada sektor informal. Banyak dari penduduk Indonesia yang belum memahami pentingnya memiliki asuransi kesehatan. Oleh karena itu mulai 1 Januari 2014, program-program jaminan kesehatan sosial yang telah diselenggarakan oleh pemerintahan dialihkan kepada BPJS Kesehatan. Pemerintah mengoperasikan BPJS Kesehatan yang ditetapkan di dalam Undang-Undang Nomor 24 Tahun 2011 tentang Badan Penyelenggara Jaminan Sosial (BPJS). Kepesertaan pada program JKN yang diselenggarakan oleh BPJS Kesehatan berdasarkan Peraturan Presiden Nomor 111 tentang Perubahan Atas Peraturan Presiden Nomor 12 Tahun 2013 tentang Jaminan Kesehatan, terbagi atas dua. Pertama, peserta PBI (Penerima Bantuan Iuran) merupakan peserta yang menerima bantuan social dari pemerintah pusat (Jamkesmas) atau pemerintah daerah (Jamkesda). Kedua, peserta non PBI yang terbagi atas peserta PPU (Pekerja Penerima
JURNAL ILMU ADMINISTRASI PUBLIK

Email : ¡ianfis.unp@gmail.com

Vol.2 No.1 Maret 2019

Upah), PBPU (Pekerja Bukan Penerima Upah) dan Bukan Pekerja (BP).

$$
\text { Mitchell (Wiener, 2012) }
$$

menyatakan bahwa memungut dan mengumpulkan iuran dari pekerja sektor formal lebih mudah dilakukan oleh pemberi kerja sedangkan pekerja sektor informal membutuhkan proses dan prosedur yang berbeda. Kebanyakan peserta PBPU adalah pekerja yang memiliki usaha sendiri tanpa ada hubungan formalitas kerja yang menerima upah tidak tetap atau menentu. BPJS Kesehatan Cabang Padang memiliki kewajiban untuk menyampaikan informasi mengenai program Jaminan Kesehatan Nasional dan prosedur pendaftarann kepada masyarakat khususnya kota Padang. Berdasarkan pernyataan Buk Eva, Kepala Unit Pemasaran BPJS Kesehatan Cabang Padang bahwa pelaksanaan sosialisasi telah dilaksanakan bagi seluruh penduduk di Kota Padang melalui media cetak dan media massa. Namun sosialiasi tersebut hanya diperoleh bagi peserta atau calon peserta PBPU yang datang di kantor cabang saat sosialisasi dilaksanakan.

Melalui sosialisasi disampaikan mengenai program JKN yang memberikan penawaran kepada masyarakat seperti biaya iuran rutin asuransi kesehatan yang digolongkan terjangkau oleh semua kalangan masyarakat disbanding asuransi swasta. Namun kemudahan tersebut belum menjadi alas an bagi masyarakat untuk bersikap positif dalam asuransi kesehatan yang ditawarkan BPJS Kesehatan.

Afwil Husni (Husni, 2016) menemukan bahwa masih rendahnya tingkat kesadaran masyarakat kota Padang akan pentingnya memiliki asuransi kesehatan berpengaurh terhadap sikap pelanggan. Misalnya mereka akan merasa rugi karena telah membayar iuran namun mereka tidak jatuh sakit. Hingga Oktober 2016, kepesertaan program JKN di Kota Padang sudah mencapai 723.557 orang dimana peserta nonPBI yakni sebesar 452.183 orang sebesar $62.49 \%$. data ini 


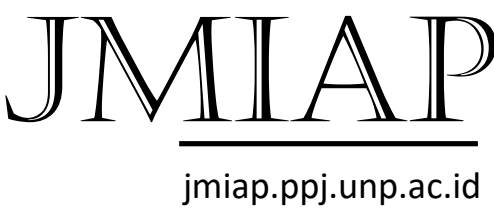

menunjukkan bahwa kontribusi peserta PBPU di Kota Padang cukup besar pada system pembiayaan program JKN.

Namun berdasarkan data BPJS Kesehatan Cabang hingga April 2016 dapat diketahui bahwa terdapat $22,75 \%$ dari jumlah peserta PBPU yang menunggak atau belum rutin membayar iuran setiap bulannya. Nugroho (Setiadi, 2015) menyatakan bahwa respon seperti perasaaan senang atau tidak senang pelanggan pada objek yang dipertanyakan secara konsisten.. Sikap peserta PBPU untuk rutin membayar iuran setiap bulannya merupakan wujud keyakinan dan rasa senang peserta terhadap layanan BPJS Kesehatan.

Namun masalah kepatuhan peserta BPJS Kesehatan yan masih rendah dari temuan penelitian Husni (Husni, 2016) terhadap peserta PBPU pada kelas 2 berada ditingkat kepercayaan peserta terhadap BPJS Kesehatan dalam mengelola Jaminan Kesehatan Nasional. Ia menemukan bahwa ketika rumah sakit sebagai penyedia layanan tidak dapat memeberikan pelayanan sesuai harapan dan menimbulkan kekecewaaan maka terbentuklah opini bahwa BPJS Kesehatan tidak mampu memberikan perlindungan terhadap hak pesertanya. Banyaknya informasi yang memaparkan informasi tentan perbedaan pelayanan yang diterima oleh peserta BPJS Kesehatan dengan peserta umum mengakibatkan rasa kepercayaan dan rasa aman peserta menurun. Bukan saja informasi mengenai perbedaan pelayanan yang diterima, namun informasi mengenai rencana-rencana ataupun peraturan yang dikeluarkan oleh pihak BPJS Kesehatan mengakibatkan kekhawatiran masyarakat terhadap BPJS Kesehatan. Salah satunya yaitu rencana kenaikan iuran bagi peserta PBPU yang terdapat dalam Peraturan Presiden RI Nomor 19 Tahun 2016 tentang Perubahan Kedua Atas Peraturan Presiden Nomor 12 Tahun 2014 tentang Jaminan Kesehatan. BPJS Kesehatan akan
JURNAL ILMU ADMINISTRASI PUBLIK

Email : jianfis.unp@gmail.com Vol.2 No.1 Maret 2019

memberlakukan tarif iuran baru per April 2016.

Dari permasalahan di atas penulis tertarik untuk melakukan penelitian dengan judul penelitian "Pengaruh Kualitas Pelayanan terhadap Kepercayaan Peserta PBPU BPJS Kesehatan pada BPJS Kesehatan Cabang Padang di Kota Padang“.

\section{Kerangka Konsep}

\section{Kualitas Pelayanan}

Heizer dan Render (Jubaedah, 2016) mendefinisikan kualitas sebagai kemampuan produk atau jasa memenuhi kebutuhan pelanggan. Sedangkan menurut Russel dan Taylor, kualitas adalah totalitas tampilan dan karakteristik produk atau jasa yang berusaha keras untuk memuaskan kebutuhan tertentu. Menurut Harbani (Pasolong, 2010) pelayanan didefinisikan sebagai aktivitas seseorang, kelompok dan/atau organisasi baik langsung maupun tidak langsung untuk memenuhi kebutuhan. Pelayanan adalah kegiatan yang menguntungkan dan menawarkan kepuasan.

Salah satu tujuan utama dalam penyelenggaraan administrasi publik oleh organisasi menurut Nora Eka Putri (N. E. Putri, 2014) yakni melaksanakan pelayanan publik terkait dengan penyelenggaraan jasajasa publik, urusan-urusan publik serta pelayanan publik yang adil. Organisasi memberikan pelayanan publik sesuai dengan kepentingan dan kebutuhan yang publik inginkan. Dimana pelayanan yang sesuai tersebut dapat memuaskan kebutuhan publik.

Maka kualitas pelayanan adalah tampilan dan karakteristik produk atau jasa yang diberikan oleh seseorang, kelompok, dan/atau organisasi melalui berbagai bentuk kegiatan pelayanan dalam memenuhi dan memuaskan kebutuhan pelayanan.

Untuk mengetahui kualitas pelayanan yang dirasakan secara nyata oleh konsumen, terdapat lima indikator kualitas 


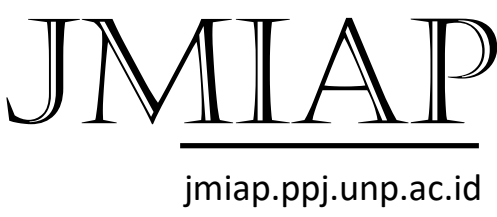

pelayanan oleh Zeithaml (Sangadji, 2013) yaitu:

1) Tangible (produk-produk fisik) merupakan penampilan fasilitas fisik berkaitan dengan ketersediaan dan daya tarik fisik, perlengkapan dan sarana komunikasi, serta penampilan karyawan.

2) Realibility (keandalan), berkenaan dengan kemampuan untuk memberikan pelayanan secara tepat dan dipercaya, seperti memberikan jasa dan cara yang sama sesuai dengan jadwal yang telah dijanjikan, dan tanpa melakukan kesalahan.

3) Responsiveness (daya tanggap), berkaitan dengan kemampuan para karyawan untuk bersedia membantu pengguna jasa dan merespons permintaan mereka.

4) Assurance (jaminan), yaitu meliputi pengetahuan, kesopanan, dan dapat menghilangkan rasa keragu-raguan konsumen dan membuat mereka merasa nyaman.

5) Emphaty (empati), yaitu memberkan perhatian ssecra individuial dan memahami keperluan setiap pelanggan dengan menjalin komunikasi sesuai yang dibutuhkan pelanggan.

Krajewski dan Ritzman (Jubaedah, 2016), kualitas memiliki lima dimensi, antara lain: Conformance to specification (kesesuaian barang atau jasa), Value (nilai produk atau jasa untuk mencapai tujuan), Fitness for use (kecocokan untuk digunakan), Support (dukungan perusahaan terhadap produk atau jasa) dan Psychological impression (kesan psikologis seperti sitra atau estetika).

Fandy (A. dan M. A. Frinaldi, 2015) menyarankan bahwa kepuasan atau tidaknya konsumen dapat ditekankan pada tanggapan positif atau negatif mereka mengenai pelayanan yang mereka terima. Perbandingan antara pengalaman mereka ketika menerima pelayanan dalam
JURNAL ILMU ADMINISTRASI PUBLIK

Email : ¡ianfis.unp@gmail.com

Vol.2 No.1 Maret 2019

kenyataan dan perkiraan mereka sebelumnya akan menciptakan respon puas atau tidak.

\section{Kepercayaan}

Menurut Paulou, P.A. dan Gefen, D yang dikutip oleh Fitra (Hidayat, 2012), mengungkapkan bahwa kepercayaan adalah suatu penilaian hubungan seseorang dengan yang lain yang melakukan kegiatan transaksi didasarkan pada harapan bahwa pihak lain yang dipercaya akan memenuhi semua kewajibannya. Sementara itu, Yousafzai dalam Elsi Fitria (Fitria, 2016) mengungkapkan trust adalah kepercayaan pihak tertentu terhadap yang lain pada saat hubungan transaksi dilakukan yang didasarkan pada keyakinan bahwa organisasi tersebut dapat memenuhi harapan pelanggan.

Barnes (Barnes, 2003) menekankan bahwa salah satu unsur yang penting dalam menjalin hubungan dengan pelanggan adalah fokus kepada ketahanan pelanggan. Tujuan dari hubungan yang terjalin yaitu kepuasan jangka panjang dengan individual.hubungan terbangun dengan pelanggan dengan memahami dan memenuhi layanan yang sesuai dengan harapan konsumen.

Luarn dan Lin mengemukakan bahwa terdapat empat komponen penting dalam membangun kepercayaan yaitu: (Luarn, 2003)

1) Perceive good integrity, konsumen harus percaya bahwa perusahaan tidak akan melakukan tindakan yang memanfaatkan kesempatan yang merugikan konsumen yang akan menyebabkan mereka meninggalkan perusahaan.

2) Benevolance, yakni itikad baik dan keyakinan bahwa suatu pihak akan dilindungi sehingga timbul rasa aman pada pelanggan.

3) Competence, yakni kemampuan yang dimiliki oleh perusahaan untuk memenuhi harapan pelanggan. 


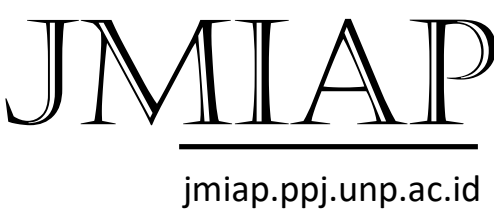

4) Predictability attributs, direfleksikan oleh pelanggan yang mengatakan mereka berurusan dengan perusahaan tertentu dengan percaya mereka dapat memenuhi kebutuhannya.

Setiap instansi pemerintah memiliki "kelompok pelanggan". Publik sebagai pelanggan menurut Skelcher (Jubaedah, 2016), dinyatakan sebagai individu yang memiliki kekuasaan dalam menetapkan kualitas pelayanan. Kepuasan yang dirasakan pelanggan atas pengalaman yang mereka alami terhadap pelayanan yang diberikan instansi yang akan menimbulkan tanggapan dari pelanggan baik positif atau negatif. Perbandingan pengalaman ketika mereka menerima pelayanan dalam kenyataan dan perkiraan mereka sebelumnya akan menciptakan rasa puas dan keyakinan bahwa organisasi atau instansi mampu memenuhi kebutuhan yang mereka perlukan.

Farida Jasfar menyatakan bahwa perusahaan yang menyediakan jasa dan menawarkan pembelian produk yang tidak dapat dilihat kepada konsumen yang membeli sebelum merasakannya perlu untuk meningkatkan kepercayaan dengan megurangi ketidakpastian kepada pelanggan.(Jasfar, 2009)

\section{Metode Penelitian}

Penelitian ini menggunakan metode pendekatan asosiatif kuantitatif. Dimana penelitian ini dilakukan untuk mengetahui
JURNAL ILMU ADMINISTRASI PUBLIK

Email : ¡ianfis.unp@gmail.com Vol.2 No.1 Maret 2019

pengaruh sebab-akibat dari varibel bebas dan variabel terikat (Sugiyono, 2009). Peneliti menyebarkan angket kepada peserta PBPU BPJS Kesehatan di Kota Padang dengan sampel 398 peserta PBPU. Penelitian ini menggunakan teknik accidental sampling dan menggunakan skala Likert. Pengumpulan data dilakukan dengan menggunakan teknik studi pustaka dan observasi. Metode penilaian yang digunakan dengan peneliti yaitu uji hipotesis dengan uji $\mathrm{t}$ (secara parsial). Penelitian asosiatif digunakan untuk menguji besarnya pengaruh secara parsial setiap variabel bukti fisik, kehandalan, daya tanggap, jaminan dan empati terahadap kepercayaan peserta PBPU BPJS Kesehatan pada BPJS Kesehatan Cabang Padang di Kota Padang.

\section{PEMBAHASAN}

\section{Hasil Penelitian}

Pada penelitian ini data yang telah dikumpulkan dan diolah menggunakan SPSS versi 16.0 dan memenuhi uji normalitas, uji linearitas, uji heteroskedastisitas, dan uji multikoleniaritas. Kemudian dilakukan uji regresi dan uji hipotesis.

Uji regresi dilakukan secara simultan melalui sub variabel kualitas pelayanan yang terdiri dari bukti fisik (tangible), kehandalan (realibility), daya tanggap (responsiveness), jaminan (assurance), dan empati (emphaty) terhadap kepercayaan maka hasilnya sebagai berikut:

Tabel 1 Hasil Kontribusi Variabel $X_{1}, \mathbf{X}_{2}, \mathbf{X}_{3}, \mathbf{X}_{4}$, dan $\mathbf{X}_{5}$ Terhadap Variabel $\mathbf{Y}$

\begin{tabular}{|l|c|r|r|r|r|}
\hline Model & $\mathrm{R}$ & $\begin{array}{c}\mathrm{R} \\
\text { Square }\end{array}$ & $\begin{array}{c}\text { Adjusted } \\
\text { R Square }\end{array}$ & $\begin{array}{c}\text { Std. Error of the } \\
\text { Estimate }\end{array}$ & Durbin-Watson \\
\hline 1 & $.423^{\mathrm{a}}$ & .179 & .168 & .39074 & 1.515 \\
\hline
\end{tabular}

a. Predictors: (Constant), Empati, Kehandalan, Bukti Fisik, Jaminan, Daya Tanggap

b. Dependent Variable: Kepercayaan 


\section{JMIAP \\ jmiap.ppj.unp.ac.id}

Pada tabel 1 nilai Adjusted $R$ Square sebesar 0.168 , artinya besarnya pengaruh buki fisik, kehandalan, daya tanggap, jaminan dan empati terhadap kepercayaan $16.8 \%$. Kemudian untuk memperkuat interpretasi bahwa pengaruh bukti fisik, kehandalan, daya tanggap, jaminan, dan empati terhadap kepercayaan adalah signifikan dapat dilihat dari tabel anova $(\mathrm{F})$ berikut ini:

Tabel 2 Hasil Uji Anova (F) Variabel $X_{1}, X_{2}, X_{3}, X_{4}$, dan $X_{5}$

Terhadap Variabel Y

\begin{tabular}{|c|c|c|c|c|c|c|}
\hline \multicolumn{2}{|c|}{ Model } & $\begin{array}{l}\text { Sum of } \\
\text { Squares }\end{array}$ & $\mathrm{df}$ & $\begin{array}{c}\text { Mean } \\
\text { Square }\end{array}$ & $\mathrm{F}$ & Sig. \\
\hline \multirow[t]{3}{*}{1} & Regression & 13.027 & 5 & 2.605 & 17.064 & $.000^{\mathrm{a}}$ \\
\hline & Residual & 59.851 & 392 & .153 & & \\
\hline & Total & 72.878 & 397 & & & \\
\hline
\end{tabular}

a. Predictors: (Constant), Empati, Kehandalan, Bukti Fisik, Jaminan, Daya Tanggap

Berdasarkan tabel 2 nilai signifikansi kualitas pelayanan terhadap kepercayaan adalah sebesar 0.000, artinya signifikansi uji nilainya lebih kecil dari 0.05. Dengan kata lain $\mathrm{H}_{0}$ ditolak dan yang diterima adalah $\mathrm{H}_{\mathrm{a}}$ dengan penjelasan secara simultan bukti fisik, kehandalan, daya tanggap, jaminan, dan empati berpengaruh terhadap kepercayaan. Untuk menguji signifikan konstanta maka dilakukan uji $\mathrm{T}$. dari uji $\mathrm{T}$ yang telah dilakukan dapat dilihat pada tabel berikut:

Tabel 3 Hasil Uji T Variabel $X_{1}, X_{2}, X_{3}, X_{4}$, dan $X_{5}$

Terhadap Variabel $Y$

Coefficients $^{\mathbf{a}}$

\begin{tabular}{|c|c|c|c|c|c|c|}
\hline \multirow{2}{*}{\multicolumn{2}{|c|}{ Model }} & \multicolumn{2}{|c|}{$\begin{array}{c}\text { Unstandardized } \\
\text { Coefficients }\end{array}$} & \multirow{2}{*}{$\begin{array}{c}\begin{array}{c}\text { Standardized } \\
\text { Coefficients }\end{array} \\
\text { Beta }\end{array}$} & \multirow[b]{2}{*}{$\mathrm{t}$} & \multirow[b]{2}{*}{ Sig. } \\
\hline & & $\mathrm{B}$ & Std. Error & & & \\
\hline \multirow[t]{6}{*}{1} & (Constant) & 1.623 & .234 & & 6.927 & .000 \\
\hline & Rata-Rata Bukti Fisik & .127 & .043 & .144 & 2.931 & .004 \\
\hline & Rata-rata Kehandalan & .057 & .055 & .056 & 1.038 & .300 \\
\hline & Rata-rata Daya Tanggap & .063 & .047 & .077 & 1.354 & .177 \\
\hline & Rata-rata Jaminan & .176 & .042 & .219 & 4.170 & .000 \\
\hline & Rata-rata Empati & .111 & .049 & .122 & 2.267 & .024 \\
\hline
\end{tabular}

a. Dependent Variable: Rata-rata Kepercayaan

Sumber: Hasil olahan data penelitian (2018) 


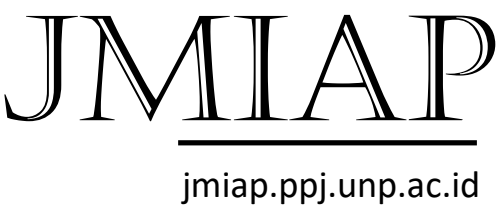

Dari hasil uji $t$ didapat nilai signifikansi sebesar 0.000 yang lebih kecil dari 0.05 sehingga disimpulkan bahwa $\mathrm{H}_{0}$ ditolak dan berarti terdapat pengaruh yang signifikan dari kualitas pelayanan terhadap kepercayaan peserta PBPU BPJS Kesehatan di Kota Padang.

Hasil penelitian yang dilakukan menunjukkan hasil yang signifikan 0.004

Variabel daya tanggap tidak berpengaruh signifikan terhadap kepercayaan. Hasil penelitian yang dilakukan menunjukkan hasil yang signifikan 0.177 yang menunjukkan bahwa daya tanggap tidak berpengaruh terhadap kepercayaan. variabel jaminan berpengaruh signifikan terhadap kepercayaan. Hasil penelitian yang dilakukan menunjukkan hasil yang signifikan 0.000 yang menunjukkan bahwa jaminan berpengaruh terhadap kepercayaan dengan kontribusi sebesar $11.2 \%$. variabel empati berpengaruh signifikan terhadap kepercayaan. Hasil penelitian yang dilakukan menunjukkan hasil yang signifikan 0.024 yang menunjukkan bahwa empati berpengaruh terhadap kepercayaan dengan kontribusi sebesar $8.8 \%$.

\section{Pembahasan}

Dalam penelitian ini ditemukan bahwa selain menghasilkan pengaruh secara sendiri-sendiri, variabel bukti fisik, kehandalan, daya tanggap, jaminan dan empati secara bersama-sama juga memberikan pengaruh yang signifikan terhadap kepercayaan peserta PBPU dengan nilai kontribusi sebesar $16.8 \%$. Hasil penelitian ini selaras dengan penelitian yang dilakukan oleh Steven dan Yohanes yang menunjukkan bahwa kualitas layanan yang diberikan bagi pelanggan yang dibagi dalam bukti fisik, kehandalan, daya tanggap, jaminan dan empati. Sehingga dari kualitas layanan tersebut dapat meningkatkan kepercayaan dari pelanggan yang dibagi dalam benevolence, reliability,
Email : jianfis.unp@gmail.com

Vol.2 No.1 Maret 2019

yang menunjukkan bahwa bukti fisik berpengaruh terhadap kepercayaan dengan kontribusi sebesar $5.7 \%$. Variabel kehandalan tidak berpengaruh positif dan signifikan terhadap kepercayaan. Hasil penelitian yang dilakukan menunjukkan hasil yang signifikan 0.300 yang menunjukkan bahwa kehandalan tidak berpengaruh terhadap kepercayaan.

competence, honesty

dan openness.(Darwin, 2014)

Selaras dengan pernyataan Aldri dan Muhammad Ali (A. dan M. A. Frinaldi, 2012) yang menjelaskan bahwa pelayanan publik berkaitan kepada pelayanan yang dirasakan pada setiap orang yang mengalami setiap aktifitas pada kelompok atau perorangan dan dimana kepuasan merupakan hasil yang tidak secara langsung berhubungan dengan produk fisik. Menurut Ryzin (Lanin, 2017) kepuasan pelanggan merupakan ringkasan konsumen atau ringkasan masyarakat tentang produk atau layanan.

Kepuasan yang dirasakan pelanggan atas pengalaman yang mereka alami terhadap pelayanan yang diberikan instansi yang akan menimbulkan tanggapan dari pelanggan baik positif atau negatif. Perbandingan pengalaman ketika mereka meneriam pelayanan dalam kenyataan dan perkiraan mereka sebelumnya akan menciptakan rasa puas dan keyainan bahwa organisasi atau instansi mampu memenuhi kebutuhan yang mereka perlukan. Menurut James Barnes (Barnes, 2003) bahwa pengalaman yang timbul akan menciptakan hubungan antara perusahaan dengan pelanggan. Dimana timbulnya kepercayaan diantara pihak terkait dilihat dari perceive good integrity, benevolence, dan competence.

Farida (Jasfar, 2009) menyatakan bahwa perusahaan yang menyediakan jasa dan menawarkan pembelian produk yang tidak dapat dilihat oleh konsumen yang membeli sebelum merasakannya perlu untuk meningkatkan kepercayaan dengan 


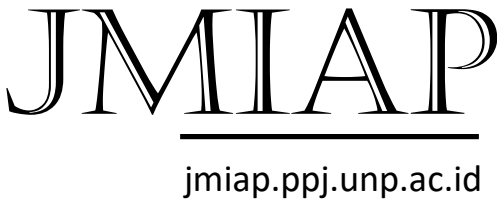

megurangi ketidakpastian kepada pelanggan.

Dhika Amalia (Kurniawan, 2016) menemukan bahwa perilaku konsumen pada kelompok informasi tinggi dapat meningkatkan hubungan antara kualitas pelayanan dan kepuasan konsumen, sedangkan perilaku kelompok informasi rendah tidak ada hubungan karena kurangnya pengetahuan dan sedikitnya informasi yang diperoleh individu mengenai kualitas pelayanan yang diterapkan di BPJS. Maka informasi memoderasi pengaruh kualitas pelayanan pada kelompok informasi rendah dan tinggi. Berdasarkan hasil penelitian Novia (N. C. M. Putri, 2015), ia menyatakan bahwa masih banyak dari responden yang belum memahami infromasi mengenai BPJS Kesehatan walaupun tingkat kepuasan BPJS Kesehatan cukup baik. Dan hasil penelitian Afwil Husni (Husni, 2016) menambahkan bahwa masih rendahnya tingkat kesadaran masyarakat akan pentingnya memiliki asuransi kesehatan berpengaruh terhadap sikap pelanggan. Misalnya mereka akan merasa rugi karena telah membayar iuran namun mereka tidak jatuh sakit. Selain itu hasil temuan Aldri dan Dede (Frinaldi, 2014) bahwa salah satu alasan banyak masyarakat yang memiliki asuransi BPJS Kesehatan kebanyak dari kelompok masyarakat berpendapatan cukup rendah, sehingga mereka memilih untuk mendapatkan perawatan kesehatan di luar. Hal ini bukan karena jaminan kesehatan lebih baik, namun karena mereka merasa dapat didengar, mendapatkan informasi yang jelas dan merasa lebih nyaman.

Selaras dengan hasil penelitian Nora Eka Putri (N. E. Putri, 2014) bahwa masih banyak dari masyarakat di Kota Padang yang belum menggunakan atau memanfaatkan layanan fasilitas yang diberikan kepada mereka melalui BPJS Kesehatan. Karena masyarakat belum menerima sosialisasi yang terakomodasi
Email : jianfis.unp@gmail.com

Vol.2 No.1 Maret 2019

dengan baik dari pemerintah. Dimana diketahui bahwa para peserta merupakan pekerja pada sektor informal atau sebagai ibu rumah tangga.

Berbeda dengan perilaku masyarakat Indonesia mengenai asuransi kesehatan Inke Mathauer dkk (Mathauer, 2008) dalam penelitian mereka menemukan bahwa pekerja sektor informal di Kenya yang sudah memiliki kesadaran untuk saling membantu diantara mereka sebelum mereka memahami asuransi kesehatan yang diterapkan. Namun selaras dengan di Indonesia, pekerja sektor informal khawatir terhadap iuran yang mereka bayarkan kepada pengelola. Walau mereka tidak akan sakit dalam waktu yang panjang. Sulit untuk mereka dapat beradaptasi dan menerima mekanisme pembayaran sesuai asuransi kesehatan yaitu dengan pembayaran perbulan sesuai kategori yang telah ditentukan. Inke menemukan bahwa mekanisme tersebut kurang adil bagi mereka yang berpenghasilan cukup rendah.

\section{KESIMPULAN}

Penelitian ini bertujuan untuk menganalisa pengaruh kualitas pelayanan yang terdiri dari bukti fisik, kehandalan, daya tanggap, jaminan dan empati terhadap kepercayaan peserta PBPU BPJS Kesehatan pada BPJS Kesehatan Cabang Padang di Kota Padang. Berdasarkan hasil penelitian ditemukan terdapat pengaruh yang signifikan secara simultan bukti fisik, kehandalan, daya tanggap, jaminan dan empati terhadap kepercayaan. Sedangkan secara parsial (sendiri-sendiri) variabel bukti fisik, jaminan dan empati berpengaruh signifikan terhadap kepercayaan peserta PBPU di BPJS Kesehatan Cabang Padang. Pada variabel kehandalan dan daya tanggap tidak terdapat pengaruh yang signifikan terhadap kepercayaan peserta PBPU di BPJS Kesehatan Cabang Padang.

Penelitian ini merekomendasikan agar BPJS Kesehatan Cabang Padang bisa 


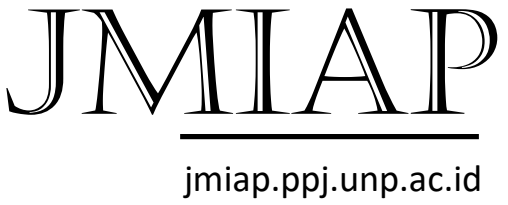

lebih meningkatkan kualitas pelayanannya terutama bagi peserta PBPU yang merupakan pekerja sektor informal yang memiliki peran cukup besar dalam mekanisme pembiayaan BPJS Kesehatan. Untuk meningkatkan kualitas pelayanan khususnya penyampaian informasi mengenai pentingnya asuransi kesehatan dan ketentuan hak dan kewajiban peserta. Sehingga peserta PBPU memahami peran mereka dalam BPJS Kesehatan yakni untuk dapat menerapkan prinsip gotong royong. BPJS Kesehatan diharapkan lebih meningkatkan jaminan terhadap hubungan kerjasama mitra yang dijalin dengan fasilitas kesehatan yang menjadi penyedia pelayanan kesehatan bagi peserta.

Kurangnya informasi yang dimiliki oleh masyarakat khususnya peserta PBPU ,yang merupakan pekerja pada sektor informal, mengakibatkan kurangnya pemahaman dan keinginan masyarakat untuk bergabung dalam asuransi kesehatan yang dikelola oleh BPJS Kesehatan. Sedangkan pada masyarakat yang sadar untuk memiliki asuransi kesehatan berpengaruh terhadap informasi yang ada dan tersebar mengenai pengelola asuransi kesehatan.

\section{DAFTAR PUSTAKA}

Barnes, J. G. (2003). Rahasia Manajemen Hubungan Pelanggan. Yogyakarta: ANDI.

Darwin, S. dan Y. S. K. (2014). Analisis Pengaruh Kualitas Layanan terhadap Loyalitas Pelanggan dengan Kepuasan dan Kepercayaan Pelanggan sebagai Variabel Intervening pada Asuransi Jiwa Manulife Indonesia-Surabaya. Jurnal Manajemen Pemasaran Petra, 2.

Fitria, E. (2016). Pengaruh

Profesionalisme, Sikap Staf, dan

Kepuasan Masyarakat terhadap

Kepercayaan Masyarakat kepeda
Email : jianfis.unp@gmail.com Vol.2 No.1 Maret 2019

Pemerintah Lokal dalam Pelayanan Bidang Kesehatan di Kabupaten Pasaman Barat. Universitas Negeri Padang.

Frinaldi, A. dan D. P. P. (2014). Hubungan Kualitas Pelayanan Publik di Bidang Kesehatan dengan Kepuasan Masyarakat (Studi Kasus Rumah Sakit Swasta X di Kota Padang, Sumatera Barat). In Prosidingg Seminar Nasional Administrasi Negara Universitas Negeri Padang. Padag: Ilmu Administrasi Negara FIS UNP.

Frinaldi, A. dan M. A. (2012). The Impact of Ethnic Work Culture on Civil Service Work Culture (a Case Study of Work Culture Punctuality and Transparency of Public Service in Pasaman Barat). In Proceeding Public Services and Utilities. Malang: UB Press and Faculty of Administrative Science University of Brawijaya.

Frinaldi, A. dan M. A. (2015). Influence of Public Service Quality in Citizen Satisfaction (Study in Private Hospital $\mathrm{Y}$ in Padang, West Sumatera Province). Journal of Government and Politics, 6.

Hidayat, F. (2012). Peranan Eksternal Manager, Sikap Staf, Kepuasan dan Pengaruhnya terhadap Kepercayaan Masyarakat dalam Pelayanan Sosial Kesejahteraan di Kabupaten Tanah Datar. Universitas Negeri Padang.

Husni, A. (2016). Kepatuhan Hukum Peserta Badan Penyelenggara Jaminan Sosial Kesehatan Mandiri dalam Membayar Premi di Kota Padang. Universitas Bung Hatta.

Jasfar, F. (2009). Manajemen Jasa. Jakarta: Ghalia Indonesia.

Jubaedah, D. dkk. (2016). Administrasi 


\section{JMIAP \\ jmiap.ppj.unp.ac.id}

Publik untuk Pelayanan Publik. Bandung: Alfabeta.

Kurniawan, D. A. (2016). Pengaruh Persepsi Harga, Kualitas Pelayanan dan Citra terhadap Niat Konsumen untuk Word of Mouth dengan Kepuasan sebagai Variabel Mediasi (Survei pada BPJS di Kabupaten Ponorogo). Al-Tijarah, 2.

Lanin, D. dan N. H. (2017). The Reinforcement of Foreigner Satisfaction Concept in Immigration service in Indonesia. Journal of Government and Politics, 8, 201-227.

Luarn, P. and H.-H. L. (2003). A Customer Loyalty Model for E-Service Context. Journal of Electronic Commerce Reserch, 4, 156-167.

Mathauer, I. dkk. (2008). Extending Social Health Insurance to the Informal Sector in Kenya. Journal of Health Planning and Management, 23, 5168.

Pasolong, H. (2010). Teori Administrasi Publik. Bandung: Alfabeta.

Peraturan Presiden Nomor 111 tentang Perubahan Atas Peraturan Presiden Nomor 12 Tahun 2013 tentang Jaminan Kesehatan (2013).

Putri, N. C. M. (2015). Kualitas Pelayanan Kepesertaan Badan Penyelenggara Jaminan Sosial (BPJS) Kesehatan Peserta PBPU di Kabupaten Batang. Journal of Politic and Government Studies, 4.

Putri, N. E. (2014). Efektivitas Penerapan Jaminan Kesehatan Nasional Melalui BPJS dalam Pelayanan Kesehatan Masyarakat Miskin di Kota Padang. TINGKAP, Vol. X No.2

Sangadji, E. M. dan S. (2013). Perilaku Konsumen: Pendekatan Praktis
JURNAL ILMU ADMINISTRASI PUBLIK

Email : jianfis.unp@gmail.com Vol.2 No.1 Maret 2019

disertai Himpunan Jurnal Penelitian. Yogyakarta: ANDI.

Setiadi, N. G. (2015). Perilaku Kosumen. Jakarta: ANDI.

Sugiyono. (2009). Metode Penelitian Administrasi dilengkapi dengan Metode R\&D. Jakarta: Alfabeta.

Undang-Undang Nomor 24 Tahun 2011 tetang Badan Penyelenggara Jaminan Sosial (BPJS) (2011).

Undang-Undang Nomor 40 Tahun 2004 Tentang Sistem Jaminan Sosial Nasional (2004).

Wiener, M. dkk. (2012). Catatan Kebijakan SJSN Implikasi Program dan Kebijakan. Edisi 4: Pemungutan Dan Pengumpulan Iuran. 
